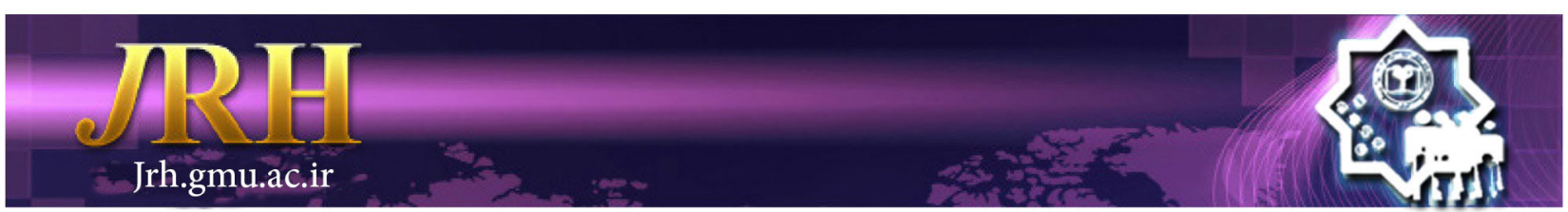

\title{
Effect of the training of the child development monitoring on stress and parenting satisfaction of mothers \\ Mojtaba Habibi ${ }^{1}$, Maryam Sedaghat ${ }^{2}$, Rahele Mohammadi ${ }^{3}$, Somaieh Salehi $^{4}$, Khalil Alizadeh ${ }^{5}$
}

\author{
Journal of Research \& Health \\ Social Development \& Health Promotion \\ Research Center \\ Vol. 9, No.3, May \& Jun 2019 \\ Pages: 246- 253 \\ DOI: $10.29252 /$ jrh.9.3.246 \\ Original Article
}

1. Correspondence to: Department of Health Psychology, School of Behavioral Sciences and Mental Health, University of Medical Sciences, Tehran, Iran

Email: Habibi.m@iums.ac.ir

2. Department of Educational Psychology, Faculty of Psychology and Education, Tehran University, Tehran, Iran

3. Department of Educational Psychology, Faculty of Psychology and Education, Tehran University, Tehran, Iran

4. Department of Counseling, Family Research Institute, Shahid Beheshti University, Tehran, Iran

5. Department of Orthopedic Surgery, Faculty of Medicine, Shahid Beheshti University of Medical Sciences, Tehran, Iran

Received: 10 Aug 2014

Accepted: 3 Feb 2015

How to cite this article: Habibi M, Sedaghat M, Mohammadi R, Salehi S, Alizadeh Kh. Effect of the training of the child development monitoring on stress and parenting satisfaction of mothers. $J$ Research \& Health2019; 9(3): 246- 253.

\begin{abstract}
The impact of stress on physical and mental health is undeniable and today, many mothers have parental stress. This study aimed to examine effect of training of growth monitoring period to reduce parenting stress and improving the level of satisfaction of mothers' parenting. Study's population included mothers of children 1 to 4 years old that in the form of available sample were selected to participate in training. 93 mothers were included in the intervention group for training and 57 mothers were included in the control group in form of quasi-experimental design. Parenting stress scale and parental satisfaction scale were used to collect data. Results showed the training of monitoring period decreased parenting stress levels and increased parenting satisfaction $(\mathrm{t}=15.29, \mathrm{p}=0.001)$. This training reduces the parent - child dysfunctional interaction, parental distress, and problematic child characteristic. It seems to help mothers during child-rearing and provide the necessary information to them about the child and their natural features and modification of mothers' false beliefs and knowledge in this field can be used for the protective role of mothers and their children in the face of stress, and facilitate the process of parenting.
\end{abstract}

Keywords: Child Development, Parenting, Stress, Satisfaction

\section{Introduction}

Stress is one of problems that modern civilized mankind is faced with it in all aspects of life. When requirements exceed the capabilities of individual and social activity, those answers which were provided are called stress [1]. Disruption of social function is including adverse behavioral effects of stress. Among manifestations of social functions can be cited parent-child interactions [2-4]. Although having child brings pleasure, pride and personal development in the mother, but it also makes many challenges so it is stressful [5-7]. Researchers have found that these challenges can cause negative side effects, so parents have high levels of anxiety and depression in comparison with those who do 
not have children. Also, parents need with their children's emotional health care beside this care of their own and continue to attract adequate social support for themselves and their families [7]. Many attempts have been done to identify the effective variables on parenting behavior in the different studies because parenting can influence on social, emotional and academic adjustment. One of these variables is parenting stress [8]. Parental perceptions of child behavior, availability of resources to assist them in their parenting and feeling competencies in connection with raising children are important elements in this definition [9]. High level of parenting stress is concerned with the lack of mother and child cooperation, greater sensitivity and intrusive parenting style [10]. Stress is also likely to increase become more pronounced objection, grueling and irritable of parents, and this in turn increases risk for conduct problems [4], oppositional defiant disorder [11], anti-social behavior [12] and Attention Deficit Disorder [13] in children. On the other hand, increased parenting stress is associated with lack of parenting positive behavior. For example, mothers who have endured a lot of stress encourage fewer prosocial skills in their children for interaction with peers in comparison of mothers who are less stressed [14]. Parenting stress in combination with other factors such as low social support [15] and anger expression [16] can be lead to more serious problems such as child abuse in parenting because child abuse plays an important role in social maladjustment in children, rejection by peers, increased aggression and reduced social competence [17-20].

Parental responsibility is the main role of prevent this situation and restore balance in the family as the main pillars of it. So parent training can be benefit to deal effectively with problems of children and cope with its stress as an important component of multidimensional approach to treat hyperactive children [21]. With review of the researches' literature in this field, it was found that parent training of ADHD children is effective in decreasing of the behavioral problems and parent-child conflicts [22].
Since in our society mothers are first and foremost responsible for nurturing and sustenance of children, any of training that enhances their parenting skills and decreases their parenting stress,it caused more satisfaction in mothers with their role and performed this responsibility better and delivers healthier children to society. As a result of the training, it would be helped to promote social health prevent the occurrence of social pathologies. In addition, with the awareness of natural process of child development and appropriate behavior for each age have not been evaluated many of the incidents stressful and mental health has not been risked. On the other hand, having the necessary awareness would be caused parents identify children's talents or defects better and faster and try to solve or bring up them. For this purpose, Sun Monitoring Design has been monitored mother and baby from the birth purposefully and systematically and besides providing training to parents in different periods of development, held meetings for the mother and child and in addition to examination of the child development, information for each age period to mothers is also provided. Effects of training on child appeared in long-term and it can be studied in school, but the effects of these educations on mothers are studied currently. Thus this study aimed to examine the parenting stress of mothers under the Monitoring process in comparison of those who did not participate in these courses. Studies have been done in the field of the mother's education and its impact on their parenting stress was in special population groups. For example, it has been observed that positive group parenting training was effective in reducing parental stress in mothers of children with Attention Deficit Hyperactivity Disorder [23]. But the mother's education had not significant effect in reducing stress of mother-child interaction, stressful characteristics of mothers and children [24]. On the one hand, the lack of studies that could be showed effect of educational efforts on mothers of normal children and on the other 
hand the lack of parenting education have been targeted programs promote awareness of parents about parenting and help them for constructive relationship with the child, shows the necessity to conduct study for examining the impact of these proceeding on parenting stress and satisfaction of child nurturing in the normal mothers. Thus, this study sought to find evidence for the hypothesis that maternal education in monitoring design reduces parental stress and increases parenting satisfaction.

\section{Method}

The population of this study included mothers with one child in 1 to 4 years old that participated in monitoring design and were benefited at least three sessions of individual trainings and monitored every six months. 57 volunteered individuals were selected to participate in this study through recall among mothers who had given birth during the last 4 years in Atieh hospital. Mothers who had one child 1 to 4 years old and time participated in the survey for the first and also did not use of specific psychological services earlier were enrolled in the study as control group. In order to control mothers' condition, only those entered in the intervention group who had one child and passing at least three sessions of personal educational and attendance for receiving the fourth session of training take at least 12 months, the age of children were at least one years old. As well as to the condition of the mothers and the problems they deal with are similar, mothers of children with four years old and older were not in educational group.

Parenting Stress Index (PSI): This index with 120-item was published in 1990 by Abidin [25]. This scale is composed of three sections and measured three main sources of tension and stress in parents. In the first part, parents' understanding of the characteristics and existing problems of child behavior is measured. The second part, the main characteristics of parents and family variables are investigated that can effect on the ability of parents to care for their children. In the third part, stressful position-demographic situations are evaluated in everyday life scenarios. Scoring from "1" to the "5" is considered for each item using Likert method with five choices. The summarized form of this scale was used in this study. Short Form has 36item with Cronbach's alpha of 0.90 and testretest reliability within 18 days after the first run, was calculated equal to 0.75 for total score of parenting stress. Three factors were extracted in the short form of the scale in Iran with the confirmatory factor analysis by using dependent three factors model. These factors included parental distress, parent-child dysfunctional interaction and problematic child characteristics [26].

Parenting Satisfaction Scale (PSS): This scale with 45 items is set by Guidubaldi and Cleminshaw. The short form that used in this study is summarized by Farmer and had 10 items. This scale is scored by using Likert 5 rate from " 1 " to completely agree to "5" to completely disagree. It had good construct validity and this scale has shown studies high internal consistency in different studies. For example, Farmer has reported Cronbach's alpha as 0.75 [27]. This scale was translated into Persian by the researcher and the Cronbach's alpha for this scale was measured 0.93 in this study.

All mothers one child in 1 to 4 years old who lives in Tehran were asked to complete the questionnaires. These mothers were benefited at least three individual sessions of Monitoring training and were supervised every 6 months. Control group who were mothers of children from one to four years old and were referred for the first time to counseling center willing to participate in the Monitoring training program individually. These mothers were asked to complete questionnaires before entering the counseling sessions. By performing a metaanalysis of stress management training for parents in children with attention deficit and hyperactivity, 17 studies were classified in the family system in the four categories of behavioral parent training, multidimensional education, cognitive-behavioral training and 
intervention [28]. The intervention program (Table 1) was prepared in the present study by using this intervention program [28], training programs for parents with children with Attention-deficit hyperactivity disorder [29,30] and several studies parent management stress intervention for with children with attention- deficit hyperactivity disorder [31-33] and also by the use of an internal investigation [33] as follows. It should be noted that the training program was carried out individually by two counselors and was conducted on mothers of normal population in Tehran at the counseling center as follows.

Table 1 The content of intervention program in each session

\begin{tabular}{|c|c|}
\hline Session & Content \\
\hline First & $\begin{array}{l}\text { Prenatal: Referrals and familiarity with pregnant mothers and their husbands, express information about the } \\
\text { mothers' needs and demands of the fetus at this stage, provide necessary training to deal with their pregnant wives } \\
\text { by husbands and effects of the arrival of a baby in the family }\end{array}$ \\
\hline Second & $\begin{array}{l}\text { After birth: Description of infants' psychological needs from birth to three months, and the features and characteristics } \\
\text { of children at this age }\end{array}$ \\
\hline Third & $\begin{array}{l}\text { Three months: Examining the psychological characteristics of the child, explaining their natural characteristics and } \\
\text { psychosocial needs, the importance of human relationships with children, appropriate games and toys for this age }\end{array}$ \\
\hline Fourth & $\begin{array}{l}\text { Six months: Examining a baby's natural characteristics by counselor, provide necessary information and training on } \\
\text { how to deal properly with children aged } 6 \text { to } 9 \text { months, learning about separation anxiety, fear of strangers. }\end{array}$ \\
\hline Fifth & $\begin{array}{l}\text { Nine months: Examining psychological, social, physical changes of the child, explaining the natural characteristics } \\
\text { and needs of this age, talk to mother about the most important concerns }\end{array}$ \\
\hline Sixth & $\begin{array}{l}\text { First year of age: Offer lessons about the independence-seeking,, language learning, curiosity and maternal behavior } \\
\text { modification procedures, answer to questions and issues that may be encountered during the next six months }\end{array}$ \\
\hline Seventh & $\begin{array}{l}\text { One and a half years old: Review of the physical, psychological, social, verbal, personality evolution, explanations } \\
\text { about eating, sleeping, bladder control, loss of milk }\end{array}$ \\
\hline Eighth & $\begin{array}{l}\text { Two years old: Study of the physical, psychological, social, verbal and personality evolution, descriptions } \\
\text { of development about thinking, language learning and teaching order, discipline and inappropriate behavior } \\
\text { modification }\end{array}$ \\
\hline Ninth & $\begin{array}{l}\text { Two and a half years old: A review of the child personality evolution, discuss ways the human relationship with the } \\
\text { children, kindergarten going, development of physical skills, thinking and creativity of children }\end{array}$ \\
\hline Tenth & $\begin{array}{l}\text { Three years old: A review and explain the natural characteristics of children, familiarity with the relaxation } \\
\text { techniques verbal and practical, learning issues of sexual curiosity, learning the role of gender, children's nightmares } \\
\text { and behavior modification techniques }\end{array}$ \\
\hline Eleventh & $\begin{array}{l}\text { Three and half years old: Education about proper play of this age, children and dealing with their natural fear, shape } \\
\text { and behavior modification techniques, training discipline, self-help skills }\end{array}$ \\
\hline Twelfth & $\begin{array}{l}\text { Four years old: About the proper play of this age, children and dealing with their natural fear, shape and behavior } \\
\text { modification techniques, training discipline, self-help skills }\end{array}$ \\
\hline Thirteenth & $\begin{array}{l}\text { Five years old: A review of developments and the needs of child growing up to } 6 \text { years; about ways of shaping the } \\
\text { behavior; how to deal with improper behavior and behavior modification techniques; numbers, words and second } \\
\text { language training }\end{array}$ \\
\hline Fourteenth & $\begin{array}{l}\text { This is a graduated meeting that will be held again a group of children at } 6 \text { years old. Review on the previous } \\
\text { contents, assess and evaluate the course of the meeting are held while holding a small celebration }\end{array}$ \\
\hline
\end{tabular}

According to the intervention program, the first step in implementing this project was inviting all mothers with children of one years old who participated minimum of six sessions of this training (A group prenatal session, a session after discharge and spend three individual session in the past). To mothers were given questionnaire of parenting stress and parenting satisfaction to complete them on the fourth day of receiving counseling. In the second step, mothers were identified who had a one years old child and for the first time referred to the center and has not been received special psychological services. They were given a questionnaire to complete while enrolling in this training. In the third step, the stress between the two parent groups were compared and analyzed and the fourth step, the training to the control group (to prevent the development of ethical considerations) immediately was began after the experimental group. All training materials, Compact Disc (CD) and educational tasks were presented to the experimental and control groups. 
The data screening and the assumption of normality was checked using the SPSS.18. The statistical analysis was done by t-test and multivariate analysis of variances (MANOVA), and significant level was checked at $\mathrm{p}<0.05$.

\section{Results}

A total of 93 mothers were in the intervention group and 57 women were in the control group. $75 \%$ of the intervention group was housewife and $25 \%$ had job. $23 \%$ of them had diploma, $66 \%$ associate degree, and $11 \%$ had postgraduate education. In the control group, $60 \%$ of mothers were housewives. $40 \%$ were employed. $42 \%$ of them had diploma, $51 \%$ of associate or bachelor's and $7 \%$ had higher education. Results of t-test to evaluate differences between parenting stress and parenting satisfaction of mothers in both groups are shown in Table 2.

Table 2 Results of t-test for significant differences between parenting stress and parenting satisfaction for both groups of mothers

\begin{tabular}{lccccccc}
\hline $\begin{array}{l}\text { Variable } \\
\text { Index }\end{array}$ & Group & $\mathrm{N}$ & Mean & $\begin{array}{c}\text { Standard } \\
\text { Deviation }\end{array}$ & $\mathrm{t}$ & $\mathrm{df}$ & $\mathrm{p}$ \\
\hline Stress & Experimental & 93 & 2.25 & 0.52 & -3.32 & 148 & 0.001 \\
Parenting & Control & 57 & 2.53 & 0.48 & & & \\
Child Satisfaction & Experimental & 93 & 3.11 & 0.51 & 15.29 & 145 & 0.001 \\
Parenting & Control & 57 & 1.79 & 0.53 & & & \\
\hline
\end{tabular}

As shown in Table 2 it is clear that parenting stress of mothers who have participated at least one year in monitoring sessions was significantly lower from those who have not received the training and referred for the first time $(\mathrm{t}=3.319, \mathrm{df}=148, \mathrm{p}<0.05)$. In addition mother's satisfaction of parenting is significantly higher than the control group $(\mathrm{t}=15.288, \mathrm{df}=145, \mathrm{p}<0.001)$.

Multivariate analysis of variance (MANOVA) was used to compare the differences between the intervention and control groups of mothers in terms subscales of parental distress, parent-child dysfunctional interaction and problematic child characteristics (dependent variables) (Table 3 ).

Table 3 Tests of between-subjects effects to comparing the parental stress mean scores for experimental V.S control in three subscales

\begin{tabular}{|c|c|c|c|c|c|c|c|}
\hline Groups & Parental stress & $\begin{array}{l}\text { Sig. for Levene's Test of } \\
\text { Equality of Error Variances }\end{array}$ & $\mathrm{df}$ & $\mathrm{F}$ & Sig. & $\begin{array}{l}\text { Partial Eta } \\
\text { Squared }\end{array}$ & $\begin{array}{l}\text { Observed } \\
\text { Power }\end{array}$ \\
\hline \multirow{3}{*}{$\begin{array}{c}\text { Experimental } \\
\text { V.S } \\
\text { Control }\end{array}$} & Parental distress & 0.228 & $1-416$ & 4.647 & 0.033 & 0.031 & 0.572 \\
\hline & $\begin{array}{l}\text { Parent-child dysfunctional } \\
\text { interaction }\end{array}$ & 0.333 & $1-416$ & 9.104 & 0.003 & 0.059 & 0.850 \\
\hline & $\begin{array}{l}\text { Problematic child } \\
\text { characteristics }\end{array}$ & 0.823 & $1-416$ & 5.424 & 0.021 & 0.036 & 0.638 \\
\hline
\end{tabular}

Assumption of homogeneity of variancecovariance matrices are established $(\mathrm{F}(94285,6.01)=0.37, \mathrm{p}>0.01)$.

The results of the experimental group and control group based on linear combinations in subscales of parenting stress indicate that there are significant differences between the two groups $(\mathrm{F}(144,3)=3.70, \mathrm{p}<0.05)$. The univariate analysis of variance was used to study the effect of group in each of the subscales. The results show that the stress of mothers in intervention group ( $\mathrm{M}=2.54)$ in subscale of the parenting stress was less than mothers in the control group $(\mathrm{M}=2.78)(\mathrm{F}(146,1)=4.64, \mathrm{p}<0.05)$. The stress of mothers in intervention group $(\mathrm{M}=1.76)$ in subscale of parent-child dysfunctional interaction was less than mothers in the control group $(M=2.04)(F(146,1)=9.11, p<0.05)$. The level of stress in intervention group $(\mathrm{M}=2.47)$ in problematic child characteristics was less than mothers in the control group $(\mathrm{M}=2.75)(\mathrm{F}$ $(146,1)=5.42, p<0.05)$. 


\section{Discussion}

Literature investigation shows that Iran has few researches about effects of coping skills training on parenting stress in mothers of normal children in this age group and this area has been somewhat neglected. It should be noted that implementing this type of research has particular importance and its results would provide appropriate guidelines to the psychologists and counselors. Therefore, this study was developed with the aim to evaluate the effectiveness of coping skills training with stress on parenting stress in mothers of normal children. As results showed Monitoring training had significant effect on reducing parenting stress and increasing parenting satisfaction of mothers. This finding is consistent with the result of the study by Roshanbin [23]. Although the mothers training was conducted in the previous study and the training was held individually in the current study. But it was noticed that the group's positive parenting would cause significant reducing in the parent domain (F 119.539, $\mathrm{p}=0.001$ ), child domain $(\mathrm{F}=672.33, \mathrm{p}=0.008)$ and components of competence and communication with husband have been improved as intervening variables in stress. But some training [24] had no effect on these variables and maternal education, had no significant effect on reducing stress of motherchild relationship, distress characteristics of the child and children's behavioral problems. Based on the results of McMahon, Forehand, and Griest [34], the reasons of lack of effectiveness include the period of the training and therapy sessions, risk characteristics of the family and family relationships, education and skills of the therapist is an important factor in the significant and continuous training of parents and family. As expected there is a significant negative correlation between parenting stress and parenting satisfaction, $(\mathrm{r}=-0.32, \mathrm{p}<0.001)$. It means that whatever with the specific ways can reduce stress during this period for mothers; to that extent it can enhance their satisfaction with parenting. Studies showed social support is an important factor to stress [35] and participate in the supportive programs reducing parenting stress [36]. Because mothers are informed of natural characteristics of children in the Monitoring process due to their age circumstances and are learned the methods of dealing with stressful children's behaviors. On the other hand, they have somebody who listens to worry and concerns that guide them beside empathy and understanding. As a result, mothers moved and pass this path with more knowledge and peace and the optimum comfort help them to be effective in training the next generation.

Parent training about issues of child development and parenting tips alter their cognitions and Studies show that changing parental cognitions have a positive effect on parenting stress and coping with stress of them [37]. Reducing parental stress levels leads them to provide more suitable environment for the growth and their potential talents of their children and will follow the progress and development of the family and society. The results of different studies in Iran showed that parent training effects on their children's behavior and modification of their attitudes [38-40]. Likely to succeed in changing the behavior of parents with their children, reduce stress and enhance their satisfaction with parenting that in turn the results of the present study corroborates the skins. This study has limitations because of the number of meetings held, the number of participants in the intervention and control groups and the study population. This program can be examined in other studies by more number of sessions and in bigger population. It is also suggested to investigators that examine the effect of coping skills training with stress in fathers. More accurate evaluate of the effect of the training program on variables such as age, education level of parents, birth order, number of siblings and parents' marital satisfaction could improve the accuracy of the efficiency and effectiveness of intervention programs in future research. One of the applied recommendations of the current study is using this study's interventionist 
program as one component of comprehensive approach to parenting and stress reduction and conduct in mothers and fathers knowledgeable programs.

\section{Conclusion}

Awareness and social support are two important elements that parents especially mothers need them extremely for parenting and having baby process. Although it is tried to design and conduct training programs for mothers of children with special problems, but it is neglected the large number of mothers who have normal children. While by appreciate training can stop parenting mistakes and unpleasant consequences with. Monitoring of child development was for training and parental support in parenting process and the present study showed with documented training and guidance of parents, especially mothers that can take a major step forward in improving parenting by reduce of parental stress and parenting satisfaction.

\section{Acknowledgements}

The authors of the study appreciate of all participants in this research.

\section{Contribution}

Study design: HM, SM, Data Collection and Analysis: HM, SM, MR Manuscript Preparation: HM, MR, AKH, SS

\section{Conflict of Interest}

"The authors declare that they have no competing interests."

\section{Funding}

The author (s) received no financial support for the research, authorship and/or publication of this manuscript.

\section{References}

1- Khodayari Fard M, Parand A. Stress and coping strategies with that. Tehran: Tehran university pub; 2008. 2- Everet CA, Everett SV. Family therapy for ADHD: Treating children, adolescents, and adults.New York, London: The Guilford press; 2001.

3- McBrurnett K, Pfiffner I. Attention deficit hyperactivity disorder: Concepts, controversies, new directions. NewYork, London: CRC press; 2008.

4- Webster-Stratton C. Stress: a potential disruptor of parent perceptions and family interactions. J Clin Child Psychol1990; 19(4): 302-12.

5- Abidin RR. Introduction to the special issue: The stresses of parenting. J Clin Child Psychol1990; 19(4): 298-301.

6- Ostberg M. Parental stress, psychosocial problems and responsiveness in help-seeking parents with small (2-45 months old) children. Acta Paediatr1998; 87(1): 69-76.

7- Crnic K, Greenberg M. Minor parenting stresses with young children. Child Dev1990; 61(5): 1628-37.

8- Abidin R. Parenting stress index professional manual. Odessa, Florida: Psychological Assessment Resources; 1995.

9- Deater-Deckard K, Scarr S. Parenting stress among dual-earner mothers and fathers: Are there gender differences? J Fam Psychol1996; 10(1): 45-59.

10- Pianta R, Egeland B. Life stress and parenting outcomes in a disadvantaged sample: Results of the mother-child interaction project. $J$ Clin Child Psychol1990; 19(4): 329-36.

11- Kazdin A. Premature termination from treatment among children referred for antisocial behavior. J Child Psychol Psychiatr1990; 31(3): 415-25.

12- Kazdin A, Mazurick J, Bass D. Risk for attrition in treatment of antisocial children and families. J Clin Child Psychol1993; 22(1): 2-16.

13- Barkley RA. Attention-deficit hyperactivity disorder: A handbook for diagnosis and treatment. New York, London: The Guilford press; 2014.

14- Peshotan Bhavnagri N. Low income African American mothers' parenting stress and instructional strategies to promote peer relationships in preschool children. Early Educ Dev1999; 10(4): 551-71.

15- Chan Y. Parenting stress and social support of mothers who physically abuse their children in Hong Kong. Child Abuse Negl1994; 18(3): 261-9.

16- Rodriguez C, Green A. Parenting stress and anger expression as predictors of child abuse potential. Child Abuse Negl1997; 21(4): 367-77.

17- Bolger K, Patterson C. Developmental pathways from child maltreatment to peer rejection. Child Dev2001; 72(2): 549-68.

18- Rogosch F, Cicchetti D. Illustrating the interface of family and peer relations through the study of child maltreatment. J Soc Dev1994; 3(3): 291-308.

19-Abidin R, Jenkins C, McGaughey M. The relationship of early family variables to children's subsequent behavioral adjustment. J Clin Child Psychol1992; 21(1): 60-9.

20- Kim J, Cicchetti D. A longitudinal study of child 
maltreatment, mother-child relationship quality and maladjustment: The role of self-esteem and social competence. Journal of Abnormal Child Psychology2004; 32(4): 341-54.

21- McCleary L, Ridley T. Parenting adolescents with ADHD: evaluation of a psychoeducation group. Patient Educ Couns 1999; 38(1): 3-10.

22- Power T, Russell H, Soffer S, Blom-Hoffman J, Grim $\mathrm{S}$. Role of parent training in the effective management of attention-deficit/hyperactivity disorder. Disease Management and Health Outcomes2002; 10(2): 117-26.

23- Roshan Bin M. Investigating the effectiveness of positive parenting group program on parenting stress for mothers with ADHD children in 4-10 ages: master dissertation, Educational psychology. Tehran: Shahid Beheshti university; 2010.

24- Ghashang N. The effectiveness of mothers in reducing tension in parent-child interaction: master dissertation, General psychology. Tehran: Shahid Beheshti university; 2004.

25- Abidin R, Brunner J. Development of a parenting alliance inventory. J Clin Child Psychol1995; 24(1): 31-40. 26- Fadaei Z, Dehghani M, Tahmasian K, Farhadei M. Investigating reliability, validity and factor structure of parenting stress-short form in mothers of 7-12 yearold children. Journal of Research in Behavioural Sciences2010; 8(2): 81-91.

27- Cutler BL. Parenting satisfaction scale (PSS). In: Cutler B. Encyclopedia of psychology and law. Los Angeles, London, New Delhi, Singapore: SAGE Pub; 2008. pp:539-41.

28- Singer G, Ethridge B, Aldana S. Primary and secondary effects of parenting and stress management interventions for parents of children with developmental disabilities: A meta-analysis. Ment Retard Dev Disabil Res Rev2007;13(4): 357-369.

29- Wells K, Epstein J, Hinshaw S, et al. Parenting and family stress treatment outcomes in attention deficit hyperactivity disorder (ADHD): An empirical analysis in the MTA study. J Abnorm Child Psychol2000; 28(6): 543-53.

30- Treacy L, Tripp G, Baird A. Parent stress management training for attention-deficit/hyperactivity disorder. Behav Ther2005; 36(3): 223-33.

31- Danforth J, Harvey E, Ulaszek W, McKee T. The outcome of group parent training for families of children with attention-deficit hyperactivity disorder and defiant/ aggressive behavior. J Behav Ther Exp Psychiatry2006; 37(3): 188-205.

32- Weinberg H. Parent training for attention-deficit hyperactivity disorder: parental and child outcome. $J$ Clin Psychol1999; 55(7): 907-13.

33- Habibi Asgarabad M, Rashidi A, Motovalipour A. Parenting stress in mothers of exceptional children versus those of normal children. Res Behav Sci J2009; 7(2): 175-80.

34- McMahon R, Forehand R, Griest D. Effects of knowledge of social learning principles on enhancing treatment outcome and generalization in a parent training program. J Consult Clin Psycho1981; 49(4): 526-32.

35- Duarte C, Bordin I, Yazigi L, Mooney J. Factors associated with stress in mothers of children with autism. Autism2005; 9(4): 416-27.

36- Shields J. The NAS early bird programme: partnership with parents in early intervention. Autism2001; 5(1): 49-56.

37- Hassall R, Rose J, McDonald J. Parenting stress in mothers of children with an intellectual disability: The effects of parental cognitions in relation to child characteristics and family support. $J$ Intellect Disabil Res2005; 49(6): 405-18.

38- Nematollahi M, Tahmasebi S. The effectiveness of parents' skills training program on reducing children's behavior problems. Journal of Family Res2014; 10(2): 159-74.

39- Cheraghi F, Rostaie Z, Asgari M, Shamsaei F, Tapak L. The effect of training of parental role on mothers' attitude with children aged 1-5 years with respect to children' abuse. Iranian Journal of Health Education and Health Promotion2017; 5(3): 182-90.

40- Alvani M. Investigating the effectiveness of family education on mother's attitude toward mental retarded children. [dissertation]. Tehran: University of Tehran 1997.

\footnotetext{
Copyright $(2016$ ASP Ins. This open-access article is published under the terms of the Creative Commons Attribution-NonCommercial 4.0 International License which permits Share (copy and redistribute the material in any medium or format) and Adapt (remix, transform, and build upon the material) under the Attribution-NonCommercial terms.
} 